УДК624.139.22:69.059.2

\title{
ИСПОЛЬЗОВАНИЕ ГОРЕЛЫХ ПОРОД ПРИ ПОДЗЕМНОЙ ПРОКЛАДКЕ КАБЕЛЬНЫХ ЛИНИЙ СВЯЗИ В КРИОЛИТОЗОНЕ
}

\author{
Галкин Александр Фёдорович1, \\ afgalkin@yandex.ru
}

\author{
Курта Иван Валентинович², \\ ivankurta@yandex.ru
}

\section{Панков Владимир Юрьевич, pankov1956@inbox.ru}

\author{
1 Институт мерзлотоведения им. П.И. Мельникова СО РАН, \\ Россия, 677010, г. Якутск, ул. Мерзлотная, 36. \\ 2 Ухтинский государственный технический университет, \\ Россия, 169300, г. Ухта, ул. Первомайская, 13. \\ 3 Северо-Восточный федеральный университет им. М.К. Аммосова, \\ Россия, 677000, г. Якутск, ул. Белинского, 58.
}

\begin{abstract}
Актуальность исследования обусловлена необходимостью освоения природных ресурсов и расширения селитебных зон арктических регионов Российской Федерации. Развитие данных территорий криолитозоны осложняется негативным влиянием криогенных процессов на строительство и эксплуатацию линейных инженерных сооружений, в частности, на подземную прокладку кабельных линий связи.

Цель: обосновать и разработать новую технологию подземной прокладки кабельных линий связи, минимизирующую влияние негативных криогенных процессов, в частности, морозобойного растрескивания грунтов, на надежность эксплуатации, без существенного увеличения трудоемкости процесса укладки кабелей на магистральных и селитебных участках.

объекты: магистральные и селитебные участки подземных кабельных линий связи в период строительства и эксплуатации. Методы: аналитические расчеты температурного режима мерзлых грунтов с целью выбора оптимальной концентрации водного раствора этиленгликоля для создания искусственной охранной грунтовой зоны вокруг кабеля; лабораторные исследования горелых пород Кильдямского месторождения для оценки целесообразности их использования в качестве защитной породной зоны вокруг кабеля.

Результаты. Проанализированы основные особенности технологий подземной укладки кабелей в деятельном слое многолетнемёрзлых грунтов. Показано, что основным фрактором, негативно влияющим на надежность кабельной связи, является образование морозобойных трещин в деятельном слое грунта в осенний период, которое приводит к повреждению оболочки, а зачастую и к полному разрушению кабеля и необходимости его замены на больших участках. Рассмотрены и проанализированы основные способы борьбы с морозобойным растрескиванием грунтов, которые рекомендуются ведомственными инструкциями для снижения влияния морозобойного растрескивания грунтов на надежность эксплуатации линий связи при подземной прокладке кабелей. Установлено, что применяемые способы либо малоэфффективны, либо экономически затратные. Предложена новая технология подземной прокладки, повышающая надежность эксплуатации кабельных линий связи при подземной прокладке на участках морозобойного(криогенного) растрескивания грунтов. Суть новой технологии состоит в том, что во время укладки кабеля часть естественного грунта деятельного слоя заменяется породой с высокими гидрофиильными свойствами (например, используют горелье породы), которую предварительно или прямо в траншее пропитьвают незамерзающей жидкостью, например, раствором этиленгликоля с концентрацией, обеспечивающей талое состояние грунта на заданной глубине. Получена формула, которая позволяет выбрать необходимое для достижения цели содержание этиленгликоля в водном растворе, в зависимости от глубины траншеи для укладки кабеля. Преимущество предлагаемой технологии по сравнению с используемыми в настоящее время заключается в возможности защищать не только кабели, проложенные в селитебных зонах, но и большие магистральнье участки кабельных линий связи, проходящие через зоны морозобойного растрескивания грунтов. Результаты экспериментальных исследований на опытном участке прокладки кабеля показали достаточную степень надежности предлагаемой технологии. В течение пяти лет наблюдений на опытном участке повреждений кабеля не было, хотя морозобойные трещины появлялись в осенне-зимний период регулярно.
\end{abstract}

Ключевые слова:

Горелая порода, защита, кабель, мерзльй грунт, криосфрера, морозобойные трещины, надежность, способ, этиленгликоль.

\section{Введение}

Защита инженерных сооружений от криогенных воздействий является актуальной проблемой для криолитозоны. Такие криогенные явления и процессы, как прогрессирующее оттаивание пород, солифлюкция, кавернообразование, пучение грунтов, морозобойное растрескивание грунтов, существенно ослож- няют строительство и эксплуатацию инженерных объектов как наземного, так и подземного размещения [1-5]. Особое место занимают подземные линейные сооружения: газо-и нефтепроводы, силовые кабели, кабели связи, поскольку относятся к важным хозяйственным объектам, обеспечивающим надежное функционирование других стратегически и экономи- 
чески важных промышленных предприятий. Исследованиям и разработке методов и способов защиты подземных линейных сооружений от криогенных воздействий уделяется достаточно большое внимание в научном и инженерном сообществах [6-13]. Наиболее широко применяющимися способами траншейной укладки кабелей в деятельном слое мерзлых грунтов являются способы, рекомендованные нормативными документами Минсвязи РФ $[14,15]$. Согласно рекомендациям, непосредственная защита кабеля должна осуществляться частичной заменой естественного грунта в траншее. А именно, предварительно, до и после укладки кабеля в траншею, в ней устраиваются нижний (постель) и верхний (засыпка) слои из песка, укрывающие кабель с двух сторон. Причем постель и засыпка делается толщиной не менее 0,1 м. Затем траншею засыпают вынутым ранее естественным грунтом. Предлагаемый способ укладки кабелей обладает рядом недостатков, которые снижают уровень надежности эксплуатации линий связи при наличии криогенных процессов. Наиболее существенным из них является увлажнение засыпки за счет проникания поверхностных вод в период дождей и таяния снега. При увлажнении постели и засыпки, песчанистые грунты которых обладают высокими фильтрационными характеристиками, и промерзании в осенний и зимний периоды происходит прочное смерзание кабеля с окружающим грунтом. При появлении на таком переувлажненном участке морозобойных трещин, глубина которых достигает нескольких метров, а ширина раскрытия у поверхности земли десятков сантиметров, ввиду того, что кабель не имеет возможности свободно перемещаться в грунте, происходят полные или частичные разрывы кабеля. Ведомственные инструкции и рекомендации по строительству и эксплуатации кабельных линий связи в деятельном слое криолитозоны рекомендуют в качестве защитной меры использовать дополнительную обмотку кабеля несколькими слоями полиэтиленовой пленки. При этом для повышения надежности между слоями пленки рекомендуется размещать незамерзающие смазки, например БАМ-3, ЦИАТИМ-201, или другие аналогичные пластинчатые смазки [15]. Этот способ, как показывают результаты лабораторных и полевых испытаний, достаточно надежен, но трудоемок и сложен в практической реализации. Кроме того, он требует существенных трудовых и экономических затрат, особенно при прокладке на магистральных участках в полевых условиях, вне селитебных зон, где длина морозобойных участков грунтов измеряется километрами. Однако в пределах селитебных зон и для защиты муфтовых соединений, наиболее подверженных негативному влиянию криогенных процессов, данный способ достаточно эффективен и надежен.

Подобная технология защиты муфтовых соединений с использованием незамерзающих смазок, являющаяся более рациональной, состоит в том, что обрабатывается не сама муфта и небольшая часть прилегающего к ней кабеля, а окружающий их грунт. В частности, засыпной грунт, который непосредственно прилегает к муфте, смешивают в равных объемах с пластинчатой смазкой (например, незамерзающей смазкой типа БАМ-3). Затем муфту укрывают этой смесью плотным слоем на 4-5 см со всех сторон. В дальнейшем траншею засыпают ранее вынутым разрыхленным грунтом и при необходимости трамбуют. Это значительно удешевляет технологию и снижает в целом трудоемкость процесса укладки кабеля. Но, к сожалению, использовать данный способ невозможно при прокладке кабелей на магистральных участках вне селитебных зон.

Целью настоящей работы являлось обоснование и разработка новой экономичной технологии прокладки кабелей в деятельном слое криолитозоны, на участках подверженных морозобойному (криогенному) растрескиванию. Основная идея состоит в том, что в традиционной технологии укладки кабеля, рекомендованной ведомственными нормативными инструкциями, часть естественного грунта деятельного слоя заменяется породой с высокими гидрофильными свойствами (например, используют горелые породы), которую предварительно или прямо в траншее пропитывают незамерзающей жидкостью, например раствором этиленгликоля с концентрацией, обеспечивающей талое состояние грунта на заданной глубине [16].

Метод. Для успешной реализации технологии на практике необходимо обеспечить талое состояние горелых пород, пропитанных незамерзающей жидкостью, в течение всего зимнего периода. Поэтому главным расчетным показателем для достижения цели является процентное содержание этиленгликоля в водном растворе. Содержание этиленгликоля должно быть равно или выше такого значения, чтобы минимальная температура пород в осенне-зимний период года на дне котлована (траншеи) $T(h)$ была равна или выше температуры замерзания водного раствора насыщающей жидкости $T$, то есть выполнялось условие $T \leq T(h)$.

Были проведены специальные лабораторные исследования, в результате которых установлено, что зависимость между процентным содержанием этиленгликоля в водном растворе (П) и температурой $\left(\mathrm{T},{ }^{\circ} \mathrm{C}\right)$, при которой водный раствор не замерзает, имеет простой линейный вид:

$$
\Pi=|2,0-1,6 * \mathrm{~T}|,
$$

где $1,6\left(\% /{ }^{\circ} \mathrm{C}\right)$ и $2,0(\%)$ - коэффициенты, полученные из опыта.

Ожидаемую температуру грунта на дне траншеи (котлована) в самый холодный период года можно определить по известной в инженерном мерзлотоведении зависимости [17]:

$$
\begin{gathered}
\mathrm{T}(h)=t_{0}-\mathrm{A}_{0} \exp (-D), \\
D=h \sqrt{\pi / \mathrm{a} \tau_{0}},
\end{gathered}
$$

где $t_{0}$ - средняя годовая температура воздуха, ${ }^{\circ} \mathrm{C} ; t_{n}-$ температура воздуха в период самой холодной пятидневки в году, ${ }^{\circ} \mathrm{C} ; \mathrm{A}_{0}=\mathrm{abs}\left(t_{0}-t_{n}\right)$ - амплитуда средних значений температуры, ${ }^{\circ} \mathrm{C} ; h$ - глубина траншеи (котлована), м; $a$ - температуропроводность засыпного грунта, м $^{2}$ ч.; $\tau_{0}-$ период от середины июля до начала самой холодной пятидневки в году, ч. 
Входящие в формулы значения параметров $\left(t_{n}\right)$ и $\left(t_{0}\right)$ для конкретной местности можно найти на специальных сайтах погоды, например гисметео, или взять из справочника [18].

Объединяя зависимости (1)-(3), несложно получить формулу для нахождения оптимального процентного содержания этиленгликоля в водном растворе, которое обеспечит круглогодичное талое состояние грунтовой постели и засыпки на заданной глубине:

$$
\Pi \geq 1,6\left[-t_{0}+\left(t_{0}-t_{n}\right) \exp (-D)\right]-2 .
$$

Обсуждение. По формуле (4) были проведены многовариантные расчеты, которые представлены в виде 3D графика на рисунке.

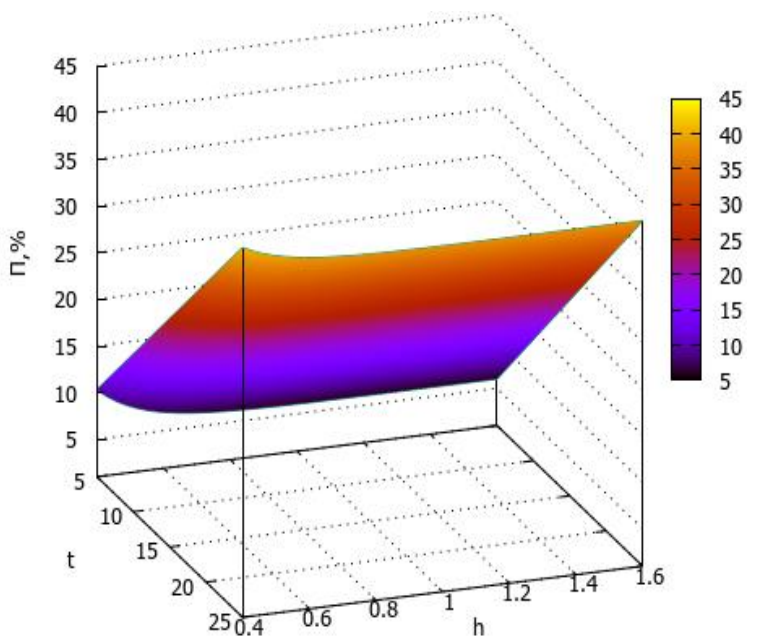

Рисунок. Оптимальная концентрация водного раствора этиленгликоля в зависимости от глубинь прокладки кабеля

Figure. Optimal concentration of aqueous solution of ethylene glycol depending on cabling depth

Из графика на рисунке видно, что основным определяющим параметром является средняя зимняя температура воздуха в районе строительства линейных сооружений связи. Глубина траншеи влияет на конечный результат только в диапазоне $0,4-0,7$ м, т. е. при неглубоком заложении кабеля. Это объясняется тепловой инерционностью мерзлого грунтового массива, деятельный слой которого в криолитозоне иногда не превышает одного метра $[19,20]$.

Для примера и пояснения сущности новой технологии рассмотрим укладку кабеля в деятельном слое дисперсного мерзлого грунта, подверженного криогенному процессу с образованием морозобойных трещин. Возьмём в качестве исходных характерные для условий криолитозоны данные: $t_{0}=-10,4{ }^{\circ} \mathrm{C}$; $t_{n}=-55^{\circ} \mathrm{C} ; \tau_{0}=4320 \mathrm{ч} ; a=4 \cdot 10^{-3} \mathrm{~m}^{2} / \mathrm{ч} ; h=1,20$ м. Используя формулу (4), найдём, что необходимое для достижения цели содержание этиленгликоля в водном растворе должно составлять около 20 \%. В качестве засыпки можно использовать любые гидрофильные горные породы, обладающие развитой капиллярной структурой, например алевролиты, туфы, известняки и т.п. В то же время наш практический опыт показы- вает, что наиболее рациональным (с технологической и экономической точки зрения) является использование природных глиежей (глины естественно жженые). Иногда их определяют как горелые породы или горелики. Отдельные разновидности этих пород являются гидрофильными и обладают хорошо развитой капиллярной структурой. Лабораторные исследования отдельных видов горелых пород показали, что их водонасыщение в насыпном состоянии по объему достигает $40 \%$ и более (были исследованы легкие глиежи из Кильдямского месторождения, расположенного в центральном районе РС(Я)). На практике новая технология укладки кабеля была реализована на опытном участке, где постоянно происходили аварии с разрывом кабеля вследствие морозобойного растрескивания грунта. На дне траншеи (глубина 1,2 м) была сделана постель из горелых пород толщиной приблизительно 10 см. Потом в траншею укладывался кабель, и производилась засыпка траншеи (на такую же толщину) слоем горелых пород. Затем методом прямого полива непосредственно в траншее пропитывали горелые породы подготовленным заранее незамерзающим водным раствором с 20\%-м содержанием этиленгликоля. Степень влагонасыщения горелых пород фиксировалась визуально: до появления слоя жидкости на поверхности горелых пород. Предварительно выполненные лабораторные исследования показали, что скорость капиллярного всасывания горелыми породами водного раствора этиленгликоля достаточно высокая при любой концентрации раствора и не должна влиять на технологичность процесса на практике при проведении строительных работ. Это подтвердилось при проведении натурного эксперимента на опытном участке. На увлажненный слой горелых пород засыпали естественный грунт, вынутый при подготовке траншеи, который после укладки послойно уплотняли с помощью вибратора. В отдельных местах опытного участка, где ожидались большие водопритоки в летнее время, между породным слоем глиежей и грунтом прокладывалась полиэтиленовая пленка. Наблюдения, которые проводились в течение пяти лет, показали, что, несмотря на появление глубоких морозобойных трещин (глубиной до 2 м с шириной раскрытия до 10 см), повреждений кабеля не было. Механизм защиты подземных кабельных линий от криогенных воздействий реализуется следующим образом. За счет того, что вокруг кабеля образуется зона незамерзающих пород, смерзания кабеля с грунтовой постелью и засыпкой не происходит. Это обеспечивает отсутствие растягивающих напряжений на поверхности кабеля при прохождении морозобойной трещины и, соответственно, его полную сохранность. По сравнению с традиционно применяемыми на практике способами защиты кабелей при траншейной прокладке в криолитозоне данная технология более надежна и экономична. Прежде всего, это обусловлено низкой, по сравнению с ценой рекомендуемых смазок, стоимостью этиленгликоля. Оценка показала, что стоимость смазок почти на порядок выше стоимости чистого этиленгликоля. Учитывая, что смазки рекомендуется использовать в соотношении один к 
одному с грунтом, а достаточная для достижения цели концентрация этиленгликоля не превышает $25 \%$, экономическая эффективность предлагаемой технологии становится очевидной. Важным элементом новой технологии является то, что, как показали результаты специальных лабораторных исследований, раствор этиленгликоля достаточно надежно «закрепляется» в порах и капиллярах горелых пород и не «вымывается» с течением времени, даже после возможных фазовых превращений. То есть технологию можно считать экологически чистой и использовать как в селитебных зонах, так и полевых районах.

\section{Заключение}

Проанализированы основные особенности технологий подземной укладки кабелей в деятельном слое многолетнемёрзлых грунтов. Показано, что основным фактором, негативно влияющим на надежность кабельных линий связи, является образование морозобойных трещин в деятельном слое грунта в осенний период. Этот процесс приводит к повреждению оболочки, а зачастую и к полному разрушения кабеля и необходимости его замены на больших участках. Рассмотрены и проанализированы основные способы борьбы с морозобойным растрескиванием грунтов, которые рекомендуются ведомственными инструкциями для снижения влияния морозобойного растрескивания грунтов на надежность эксплуатации линий связи при подземной прокладке кабелей. Установлено, что применяемые способы либо малоэффективны, либо экономически затратные. Предложена новая технология,

\section{СПИСОК ЛИТЕРАТУРЫ}

1. Zhang X., Feng S.G., Chen P.C. Thawing settlement risk of running pipeline in permafrost regions // Oil Gas Storage Transporation. - 2013. - № 6. - P. 365-369.

2. Николаева М.В., Стручкова Г.П. Прогнозирование теплового взаимодействия участка подземного трубопровода с льдистыми грунтами // Технологии нефти и газа. - 2018. - № 4 (117). C. 56-60.

3. Железняк М.Н., Сериков С.И., Шац М.М. Расширение нефтепровода «Восточная Сибирь-Тихий океан» (геоэкологические и геотехнические аспекты) // Маркшейдерия и недропользование. - 2018. - № 5 (97). - С. 59-66.

4. Xu J., Goering D.J. Experimental validation of passive permafrost cooling systems // Cold Regions Science and Technology. 2008. - № 53 (3). - P. 283-297.

5. Miller D.L., Johnson L. Pile settlement in saline permafrost: a case history // Proc. 5th Canadian Permafrost Conference. - Quebec, 1990. - P. 371-378

6. Железняк М.Н., Сериков С.И., Шац М.М. Экологогеокриологические и геотехнические условия газотранспортной системы «Сила Сибири» // Вестник ПНИПУ. Геология Нефтегазовое и горное дело. - 2018. - Т. 17. - № 2. - С. 189-200. DOI: 10.15593/2224-9923/2018.2.8

7. Железняк М.Н., Сериков С.И., Шац М.М. Газотранспортная система «Сила Сибири»: современные проблемы и перспективы // Трубопроводный транспорт: теория и практика. - 2017. № 4 (62). - С. 48-56.

8. Galkin A.F Thermal conditions of the underground town collector tunnel // Metallurgical and Mining Industry. - 2015. - № 8. P. 70-73.

9. Температурное взаимодействие подземного трубопровода с криолитозоной / Г.П. Стручкова, Т.А. Капитонова, М.В. Ни- повышающая надежность эксплуатации кабельных линий связи при подземной прокладке на участках морозобойного (криогенного) растрескивания грунтов. Суть новой технологии состоит в том, что во время укладки кабеля часть естественного грунта деятельного слоя заменяется породой с высокими гидрофильными свойствами (например, используют глиежи), которую предварительно или прямо в траншее пропитывают незамерзающей жидкостью, например, раствором этиленгликоля с концентрацией, обеспечивающей талое состояние грунта на заданной глубине. Это предотвращает смерзание кабеля с засыпным грунтом и предохраняет его от негативного воздействия криогенных процессов, в частности морозобойных трещин. Получена формула, которая позволяет выбрать необходимое для достижения цели содержание этиленгликоля в водном растворе в зависимости от глубины траншеи для укладки кабеля. Преимущество предлагаемой технологии, по сравнению с используемыми в настоящее время, заключается в возможности защищать не только кабели, проложенные в селитебных зонах, но и большие магистральные участки кабельных линий связи, проходящие через зоны морозобойного растрескивания грунтов. Результаты экспериментальных исследований на опытном участке прокладки кабеля показали достаточную степень надежности предлагаемой технологии. В течение пяти лет наблюдений на опытном участке повреждений кабеля не было, хотя морозобойные трещины появлялись в осенне-зимний период регулярно.

колаева, О.И. Слепцов // Естественные и технические науки. 2017. - № 12 (114). - C. 125-128.

10. Guizhi Liu. Study of the method laying fiber optic cable in the same trench with pipeline in permafrost region // Proceedings of the International Petroleum and Petrochemical Technology Conference. - 2018. - P. 152-158. URL: https://doi.org/ 10.1007/978-981-13-2173-3 (дата обращения 01.02.2020).

11. Tan J.D., Zheng J., Ma Y.B. Displacement monitoring of MoheDaqing oil pipeline in the permafrost frozen area // Oil Gas Storage Transp. - 2012. - № 5. - P. 737-739.

12. Gao P. Construction technical study of communication buried optical cable in plateau permafrost area of QingHai-Tibet railway // Railway Signal Communication. - 2010. - № 3. - P. 52-53.

13. Zhang T. Study of influence on optical cable from perennial frozen soil // Railway Signal Communication. - 2005. - № 3. - P. 49-50.

14. Инструкция по проектированию линейно-кабельных сооружений связи. ВСН 116.93 - М.: Минсвязь России, 1993. - 26 с.

15. Технические указания по проектированию, строительству и эксплуатации кабельных линий связи в районах вечной мерзлоты. - М.: Минсвязь СССР,1981. - 83 с.

16. Способ прокладки кабельных линий связи: патент Рос. Федерация. № 2110128, заявл. 24.10.1994; опубл. 27.04.1998. Бюл. № 4. -5 c.

17. Докучаев В.В. Расчет фундаментов на вечномерзлых грунтах по предельным состояниям. - Л.: Стройиздат, 1968. - 120 с.

18. Строительная климатология и геофизика / под ред. М.А. Кошкина. - М.: Стройиздат, 1973. - 320 с.

19. Ершов Э.Д. Общая геокриология. - М.: Изд-во Моск. ун-та. 2002. $-684 \mathrm{c}$

20. Общее мерзлотоведение (геокриология)/ под ред. В.А. Кудрявцева. - М.: Изд-во Моск. ун-та. 1978. - 463 с.

Поступила 07.02.2020 г. 


\section{Информация об авторах}

Галкин А.Ф., доктор технических наук, профессор, главный научный сотрудник лаборатории геотермии криолитозоны Института мерзлотоведения им. П.И. Мельникова СО РАН.

Курта И.В., кандидат технических наук, доцент кафедры недропользования, строительства и менеджмента Ухтинского государственного технического университета.

Панков В.Ю., кандидат геолого-минералогических наук, доцент кафедры автомобильных дорог и аэродромов Северо-Восточного федерального университета им. М.К. Аммосова. 
UDC 624.139.22:69.059.2

\title{
USE OF BURNED ROCKS IN UNDERGROUND LAYING OF CABLE LINES IN THE CRYOLITZONE
}

\author{
Aleksandr F. Galkin'1, \\ afgalkin@yandex.ru \\ Ivan V. Kurta², \\ ivankurta@yandex.ru \\ Vladimir Yu. Pankov³, \\ pankov1956@inbox.ru \\ 1 Melnikov Permafrost Institute SB RAS, \\ 36, Merzlotnaya street, Yakutsk, 677010, Russia. \\ 2 Ukhta State Technical University, \\ 13, Pervomayskaya street, Ukhta,169300, Russia. \\ 3 North-Eastern Federal University, \\ 58, Belinsky street, Yakutsk, 677000, Russia.
}

The relevance of the research is caused by the need to develop natural resources and expand the residential areas of the arctic regions of the Russian Federation. The development of these territories in the permafrost zone is complicated by the negative influence of cryogenic processes on the construction and operation of linear engineering structures, in particular, on the underground laying of cable communication lines.

The main aim of the research is to substantiate and develop a new technology for underground laying of cable communication lines that minimizes the impact of negative cryogenic processes, in particular, frost cracking of soils, on the reliability of operation, without significant increase in complexity of laying cables on the main and residential areas.

Objects: trunk and residential sections of underground cable lines during construction and operation.

Methods: analytical calculations of the temperature regime of frozen soils in order to select the optimal concentration of an aqueous solution of ethylene glycol to create an artificial protective soil zone around the cable; laboratory studies of the slopes of the Kildyamskoe field to assess the feasibility of their use as a protective rock zone around the cable.

Results. The main features of laying cable communication lines in the permafrost zone are analyzed. It was established that the main factor negatively affecting the reliability of cable communication is cryogenic processes. In particular, frost cracking of the soil of the active layer, which leads to rupture of the cables. The main methods of combating frost cracking of soils to protect cables are reviewed and analyzed. It is established that the methods used are either ineffective or economically costly. A new technology of underground laying is proposed that increases the reliability of cable communication lines in the permafrost zone. The essence of the new technology is that during cable laying, a part of the natural soil is replaced with hydrophilic rock, which is pre-saturated preliminary or directly in the trench with an ice-free aqueous solution of ethylene glycol. A formula is obtained for the optimal concentration of an aqueous solution of ethylene glycol depending on the depth of the cable. The advantage of the proposed technology for underground cable laying is that it becomes possible to protect large linear sections of soil that are subjected to frost cracking.

Key words:

Burned rocks, protection, cable, frozen soil, cryosphere, frost cracks, reliability, method, ethylene glycol.

\section{REFERENCES}

1. Zhang X., Feng S.G., Chen P.C. Thawing settlement risk of running pipeline in permafrost regions. Oil Gas Storage Transp., 2013 no. 6, pp.365-369.

2. Nikolaeva M.V., Struchkova G.P. Prediction of thermal interaction of an underground pipeline section with icy soils. Oil and Gas Technologies, 2018, no. 4 (117), pp. 56-60. In Rus.

3. Zheleznyak M.N., Serikov S.I., Shatz M.M. Expansion of the East Siberia - Pacific Ocean oil pipeline (geoecological and geotechnical aspects). Mine Surveying and Subsoil Use, 2018, no. 5 (97), pp. 59-66. In Rus.

4. Xu J., Goering D.J. Experimental validation of passive permafros cooling systems. Cold Regions Science and Technology, 2008, no. 53 (3), pp. 283-297.

5. Miller D.L., Johnson L. Pile settlement in saline permafrost: a case history. Proc. $5^{\text {th }}$ Canadian Permafrost Conference. Quebec, 1990 pp. 371-378.

6. Zheleznyak M.N., Serikov S.I., Shatz M.M. Ecological, geocryological and geotechnical conditions of the Power of Siberia gas transmission system. Bulletin of PNIPU. Geology. Oil and gas and mining, 2018, vol. 17, no. 2, pp. 189-200. In Rus. DOI: $10.15593 /$ 2224-9923/2018.2.8
7. Zheleznyak M.N., Serikov S.I., Shatz M.M. Gas transmission system «Power of Siberia»: current problems and prospects. Pipeline transport: theory and practice, 2017, no. 4 (62), pp. 48-56. In Rus.

8. Galkin A.F. Thermal conditions of the underground town collector tunnel. Metallurgical and Mining Industry, 2015, no. 8, pp. 70-73.

9. Struchkova G.P., Kapitonova T.A., Nikolaeva M.V., Sleptsov O.I The temperature interaction of an underground pipeline with a permafrost zone. Natural and Technical Sciences, 2017, no. 12 (114), pp. 125-128. In Rus.

10. Guizhi Liu. Study of the method laying fiber optic cable in the same trench with pipeline in permafrost region. Proc. of the International Petroleum and Petrochemical Technology Conference, 2018, pp. 152-158. Available at: https://doi.org/10.1007/978-98113-2173-3 (accessed 1 February 2020).

11. Tan J.D., Zheng J., Ma Y.B. Displacement monitoring of MoheDaqing oil pipeline in the permafrost frozen area. Oil Gas Storage Transportation, 2012, no. 5, pp. 737-739.

12. Gao P. Construction technical study of communication buried optical cable in plateau permafrost area of QingHai-Tibet railway. Railway Signal Communication, 2010, no. 3, pp. 52-53.

13. Zhang T. Study of influence on optical cable from perennial frozen soil. Railway Signal Communication, 2005, no. 3, pp. 49-50. 
14. Instruktsiya po proektirovaniyu lineyno-kabelnykh sooruzheniy svyazi. VSN 116.93 [ Instructions for the design of linear-cable communication facilities]. Moscow, Minsvyaz Rossii Publ., 1993. $26 \mathrm{p}$.

15. Tekhnicheskie ukazaniya po proektirovaniyu, stroitelstvu i ekspluatatsii kabelnykh liniysvyazi v rayonakh vechnoy merzloty [Technical guidelines for the design, construction and operation of cable communication lines in permafrost areas]. Moscow, Minsvyaz SSSR Publ., 1981. 83p.

16. Galkin A.F., Li S.T., Aristarhov I.M., Volovik L.Yu. Sposob prokladki kabelnykh liniy svyazi [The method of laying cable communication lines]. Patent RF, no. 2110128, 1998.

17. Dokuchaev V.V. Raschet fundamentov na vechnomerzlykh gruntakh po predelnym sostoyaniyam [Calculation of foundations on

\section{Information about the authors}

Aleksandr F. Galkin, Dr. Sc., professor, chief researcher, Melnikov Permafrost Institute.

Ivan V. Kurta, Cand. Sc., associate professor, Ukhta State Technical University.

Vladimir Yu. Pankov, Cand. Sc., associate professor, North-Eastern Federal University. permafrost soils according to limiting conditions]. Leningrad, Stroyizdat Publ., 1968. $120 \mathrm{p}$.

18. Stroitelnaya klimatologiya i geofizika [Building climatology and geophysics]. Ed. by M.A. Koshkin. Moscow, Stroyizdat Publ., 1973. $320 \mathrm{p}$.

19. Ershov E.D. Obshchaya geokriologiya [General geocryology]. Moscow, MoscowUniversity Publ., 2002. 684 p.

20. Obshchee merzlotovedenie (geokriologiya) [General permafrost (geocryology)]. Ed. by V.A. Kudryavtsev. Moscow, Moscow University Publ., 1978. $463 \mathrm{p}$.

Received: 7 February 2020. 